\title{
Comparative evaluation of calcium phosphate-based varnish and resin-modified glass ionomer-based varnish in reducing dentinal hypersensitivity: A randomized controlled clinical

\author{
Harshul Sharma ${ }^{1}$, Charu Gupta $^{1}$, Sophia Thakur ${ }^{1}$, Sanjeev Srivastava ${ }^{2}$
}

Correspondence: Dr. Harshul Sharma

'Department of Conservative Dentistry and Endodontics,

Email: harshul.thedentist@gmail.com BDCH, Davangere, Karnataka, India, ${ }^{2}$ Department of Conservative Dentistry and Endodontics, SPPGIDMS, Lucknow, Uttar Pradesh, India

\section{ABSTRACT}

Objective: The aim of this study was to evaluate the efficacy of MI varnish and Clinpro XT varnish in reducing dentinal hypersensitivity. Materials and Methods: Patients with cervical dentinal hypersensitivity were selected for the study. The teeth to be tested were isolated. Then, a blast of air and ice cold water was applied on the tooth surface, and the score was measured by visual analog scale. The patients were randomly assigned to one of the treatment groups (Group 1: MI varnish; Group 2; Clinpro XT varnish). The manufacturer's instructions were followed. The sensitivity scores were recorded immediately and after 1 week of therapy. Statistical Analysis: Mann-Whitney U-test and Wilcoxon-matched pairs test were used for the analysis. Results and Conclusion: Although both varnishes were shown to reduce the dentinal hypersensitivity in patients, according to statistics, MI Varnish was a better agent to reduce dentinal hypersensitivity than Clinpro XT varnish.

Key words: Cervical abrasion, dentinal hypersensitivity, desensitization, varnish

\section{INTRODUCTION}

Dentin hypersensitivity has been defined as a short, sharp pain arising from exposed dentin in response to stimuli, typically thermal, evaporative, tactile, osmotic, or chemical, which cannot be ascribed to any other form of dental pathology. ${ }^{[1]}$ Various theories have been proposed to explain this phenomenon, but the classic hydrodynamic theory has been most accepted. It states that fluid movement in the tubules causes increased nerve excitability thus eliciting dentinal sensitivity. ${ }^{[2]}$

\begin{tabular}{|l|l|}
\hline \multicolumn{2}{|c|}{ Access this article online } \\
\hline Quick Response Code: \\
\hline
\end{tabular}

Since thousands of years, numerous agents such as potassium oxalate, ammonium hexafluorosilicate, propolis, and dentin bonding agents have been used to treat dentinal hypersensitivity, ${ }^{[3-5]}$ but no agent or treatment regimen has proved to be a gold standard for effective treatment of dentinal hypersensitivity.

Most in-office desensitizing agents work by tubular occlusion. Earlier, the varnishes that were used Gluma (glutaraldehyde and hydroxyethyl

This is an open access article distributed under the terms of the Creative Commons Attribution-NonCommercial-ShareAlike 3.0 License, which allows others to remix, tweak, and build upon the work non-commercially, as long as the author is credited and the new creations are licensed under the identical terms.

For reprints contact: reprints@medknow.com

How to cite this article: Sharma H, Gupta C, Thakur S, Srivastava S. Comparative evaluation of calcium phosphate-based varnish and resin-modified glass ionomer-based varnish in reducing dentinal hypersensitivity: A randomized controlled clinical trial. Eur J Dent 2017;11:491-5.

DOI: 10.4103/ejd.ejd_127_17 
methacrylate), Cervitec (thymol and chlorhexidine) ${ }^{[6]}$ duraphat (Colgate, New York, USA), etc. Now newer generation varnishes have come into existence such as Clinpro XT varnish (GC America, Illinois, USA) and MI varnish (3M ESPE, California, USA).

A sodium fluoride varnish works on the principle of tubular occlusion and the presence of fluoride is thought to increase the stability of the dentin surface thus reducing the solubility of dentin and thereby shifting the equilibrium at the surface level in favor of nonsensitivity. ${ }^{[7]}$

Clinpro XT varnish, which is used for in-office treatment, acts as a dentin adhesive sealers. It is a light-cured glass ionomer-based material, which is available in a liquid/paste system. It also contains fluorides, calcium, and phosphate which help in supplementing the remineralization process ${ }^{[8]}$ and reducing dentinal hypersensitivity.

MI varnish (RECALDENT), which is used for in-office treatment, acts by plugging the dentinal tubules and is a calcium phosphate-based varnish. It is a $5 \%$ sodium fluoride-based varnish with casein phosphopeptides (CPP) which stabilizes the amorphous calcium phosphate phase to deliver bioavailable calcium, phosphate, and fluoride ions to the tooth surface to promote remineralization of tooth structure ${ }^{[9]}$ and occludes the dentinal tubules thus reducing dentin sensitivity.

The literature is replete with studies comparing fluoride varnishes, but very scarce literature is found on remineralizing varnishes used to treat dentinal hypersensitivity. ${ }^{[8]}$ Thus, the aim of this study is to evaluate the efficacy of MI varnish and Clinpro XT varnish in reducing dentinal hypersensitivity.

\section{MATERIALS AND METHODS}

Patients visiting the outpatient department with cervical dentinal hypersensitivity were selected for the study. Approval was granted by the Institutional review board and the procedures conducted were in accordance with the ethical standards of the Helsinki Declaration of 1975, as revised in 2000. All the study subjects were informed in detail about the nature of the research procedure, and a written consent was obtained. The sample size was estimated based on data obtained from published literature. ${ }^{[10]}$ The pooled standard deviation $(S)$ and mean expected difference $(d)$ was obtained from the same article. The probability of Type I error was fixed at $5 \%(Z \alpha=1.46)$. The probability of Type II error was fixed at $20 \%$ $(Z \beta=0.84)$.

The formula used to calculate the sample size is:

$$
\frac{n=\left(Z_{\alpha}-Z_{1-\beta}\right)^{2} \times 2 \times S^{2}}{d}
$$

Substituting the values,

$n=(1.46+0.84)^{2} \times(1.4)^{2} \times 2 / 1=21$

Sample size will be increased by $10 \%$ to adjust for any loss to follow-up. Hence, the final sample size is $23 \approx 25$ teeth in each group.

The inclusion criteria for patients in the study was that the teeth should have dentinal hypersensitivity caused by cervical abrasion/erosion, no dental pathology which causes pain similar to cervical dentinal hypersensitivity, ${ }^{[11]}$ should have a preoperative visual analog scale (VAS) score of $\geq 2$, age in the group of 18-50 years, and a good systemic health.

The exclusion criteria consisted of teeth with caries, defective restorations, occlusal restorations, chipped teeth, deep periodontal pockets (probing depth $>6 \mathrm{~mm}$ ), patients with ulcerative gingivitis and stomatitis and those who have undergone periodontal surgery within the previous 3 months, patients with orthodontic appliances, teeth with cervical defects $>2 \mathrm{~mm}$ horizontally, ${ }^{[11]}$ patients who have used desensitizing toothpaste in the past 3 months. Patients allergic to ingredients used in the study-CPP are derived from milk casein. Hence, patients with a proven or suspected milk protein allergy were excluded.

Before treatment, patient's demographic details and a thorough history of presenting illness were recorded. Clinical evaluation was performed using visual and tactile examination, air blast test, and cold water test. ${ }^{[5]}$

The teeth to be tested were isolated by cotton rolls and a suction device. Then, a blast of air was applied at a $0.5 \mathrm{~cm}$ distance ${ }^{[11]}$ to the tooth surface, and the score was measured by VAS in which the patient placed a pencil mark at a point on scale from 0 to 10 where, 0 is "no pain" and 10 is the "worst pain possible." This was followed by scoring of tooth sensitivity using $0.5 \mathrm{ml}$ of ice cold water ${ }^{[6]}$ applied to the exposed dentine surface while neighboring teeth were isolated during testing using the operator's fingers and cotton rolls. A period 


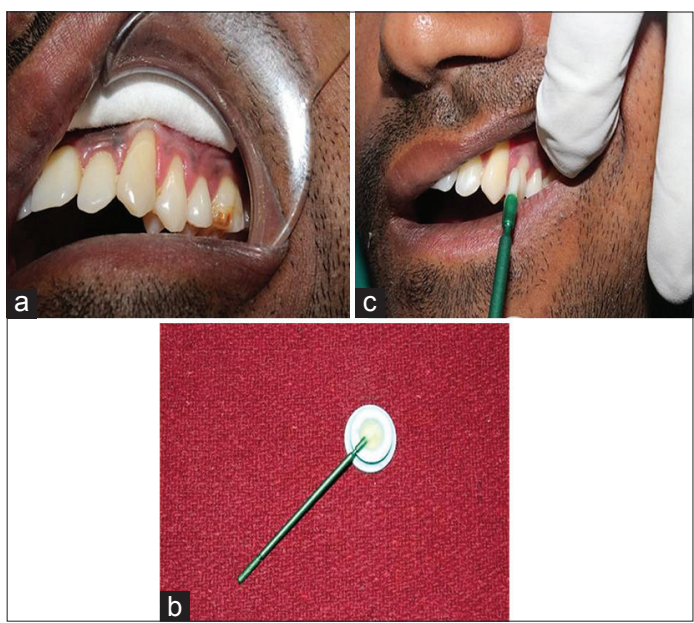

Figure 1: (a) MI Varnish Group: Preoperative. (b) MI Varnish Group: Applicator Tip and Well. (c) MI Varnish Group: Application

of at least 5 min was allowed between the two stimuli on each tooth. ${ }^{[11,12]}$

After recording the first scores, the patients were randomly assigned to one of the treatment groups. The randomization process was conducted before the clinical steps. The randomization procedure was carried out using sequentially numbered opaque-sealed envelopes prepared with simple randomization. ${ }^{[11]}$

The desensitizing agents used in the current study were Clinpro XT varnish (GC America, Illinois, USA) and MI Varnish (3M ESPE, California, USA).

The manufacturer's instructions were followed during the application of the agents [Figures 1 and 2]. Water and saliva contamination were avoided, and a dry field was maintained. The patients were instructed not to consume hard, hot or sticky foods, products-containing alcohol (oral rinses, beverages, etc.) and to avoid tooth brushing and flossing for $4 \mathrm{~h} .{ }^{[11]}$ Patients were advised to use a soft bristle tooth for brushing twice a day. Patients were directed to refrain from using any other fluoride-containing dentifrice or mouth rinse during the trial but were allowed to continue their normal oral hygiene practices. The sensitivity scores were recorded, immediately and 1 week after the therapy. At each appointment, clinical outcome was evaluated by air blast test and cold water test, ${ }^{[11]}$ and scores were evaluated using VAS. ${ }^{[12]}$

\section{Statistical analysis}

Normality of the data distribution was checked, based on which nonparametric tests were used. Kolmogorov-Smirnov Test was used for

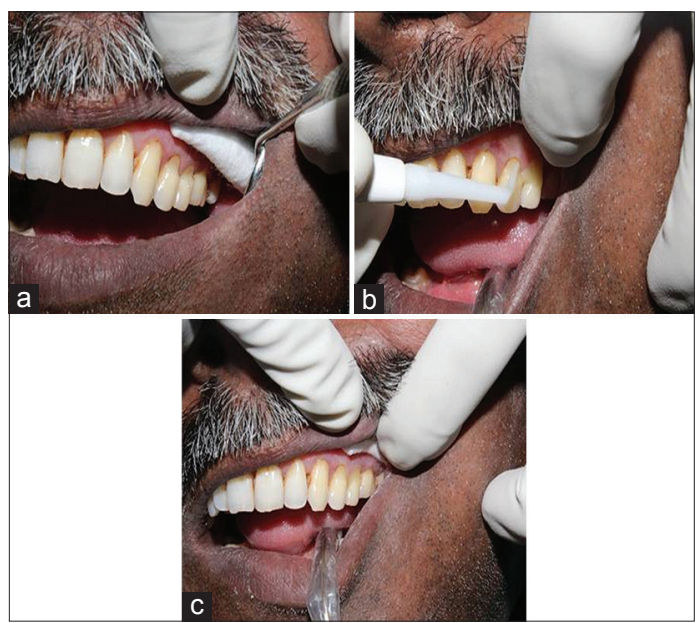

Figure 2: (a) Clinpro XT Varnish Group: Preoperative. (b) Clinpro XT Varnish Group: Application. (c) Clinpro XT Varnish Group: Postoperative

determining normality. Mann-Whitney U-test and Wilcoxon-matched pairs test were used for the analysis.

\section{RESULTS}

Overall, the group for MI Varnish has a statistically significant difference over the group for Clinpro XT Varnish in reducing dentinal hyper sensitivity when comparing the values for Ice test scores [Table 1]. The percentage of change calculated when comparing the two groups for ice test scores is greater in Group 1 than Group 2 [Graph 1].

For cold water test, [Group 1] has a statistically significant difference over Group 2 [Table 2]. The percentage of change for cold water test is approximately double when compared between Group 1 and Group 2 [Graph 2].

\section{DISCUSSION}

Dentine hypersensitivity is an enigma, being frequently encountered yet less understood. ${ }^{[13-15]}$ The basic goal in the treatment of dentinal hypersensitivity is to either seal the dentinal tubules by physical or chemical occlusion or to desensitize the nerves by causing depolarization of the cellular membrane of the nerve terminal and a refractory period with decreased sensitivity. ${ }^{[16]}$

Although subjective, the VAS scale has been shown by studies to be accurate for recording patient responses. Within the present study, an air blast was used as it is considered the best way to illicit a response of the patient. It consists of a short blast from a dental unit triple syringe at 40-65 psi and temperature between 
Sharma, et al:: A novel treatment approach to dentinal hypersensitivity

\begin{tabular}{|c|c|c|c|c|c|c|c|c|c|c|}
\hline \multirow[t]{2}{*}{ Time points } & \multicolumn{4}{|c|}{ MI varnish } & \multicolumn{4}{|c|}{ Clinpro varnish } & \multirow[t]{2}{*}{$z$} & \multirow[t]{2}{*}{$P$} \\
\hline & Median & Mean & SD & Sum of ranks & Median & Mean & SD & Sum of ranks & & \\
\hline $\mathrm{BL}$ & 4.0 & 4.2 & 1.4 & 462.0 & 6.0 & 5.8 & 1.6 & 813.0 & -3.4052 & $0.0007^{*}$ \\
\hline Immediate after & 2.0 & 1.6 & 1.2 & 398.5 & 4.0 & 3.4 & 1.1 & 876.5 & -4.6373 & $0.00001^{*}$ \\
\hline 1 week & 0.0 & 0.4 & 0.6 & 353.0 & 2.0 & 2.2 & 0.7 & 922.0 & -5.5201 & $0.00001^{*}$ \\
\hline BL-immediate after & 2.0 & 2.6 & 1.4 & 640.5 & 2.0 & 2.4 & 1.2 & 634.5 & -0.0582 & 0.9536 \\
\hline BL-1 week & 4.0 & 3.8 & 1.6 & 654.5 & 3.0 & 3.6 & 1.5 & 620.5 & -0.3298 & 0.7415 \\
\hline Immediate after-1 week & 1.0 & 1.2 & 1.1 & 619.0 & 1.0 & 1.2 & 0.7 & 656.0 & -0.3590 & 0.7196 \\
\hline
\end{tabular}

\begin{tabular}{|c|c|c|c|c|c|c|c|c|c|c|}
\hline \multirow[t]{2}{*}{ Time points } & \multicolumn{4}{|c|}{ MI varnish } & \multicolumn{4}{|c|}{ Clinpro varnish } & \multirow[t]{2}{*}{$Z$} & \multirow[t]{2}{*}{$P$} \\
\hline & Median & Mean & SD & Sum of ranks & Median & Mean & SD & Sum of ranks & & \\
\hline $\mathrm{BL}$ & 4.0 & 3.9 & 1.3 & 444.0 & 5.0 & 5.6 & 1.5 & 831.0 & -3.7545 & $0.0002^{*}$ \\
\hline Immediate after & 1.0 & 1.1 & 1.1 & 371.0 & 4.0 & 3.4 & 1.1 & 904.0 & -5.1709 & $0.00001^{*}$ \\
\hline 1 week & 0.0 & 0.2 & 0.4 & 342.5 & 2.0 & 2.2 & 0.7 & 932.5 & -5.7238 & $0.00001^{*}$ \\
\hline BL-immediate after & 3.0 & 2.8 & 1.5 & 707.5 & 2.0 & 2.2 & 1.3 & 567.5 & -1.3582 & 0.1744 \\
\hline BL-1 week & 4.0 & 3.7 & 1.4 & 673.5 & 3.0 & 3.4 & 1.5 & 601.5 & -0.6985 & 0.4849 \\
\hline Immediate after-1 week & 1.0 & 0.9 & 0.9 & 562.0 & 1.0 & 1.2 & 0.8 & 713.0 & -1.4649 & 0.1430 \\
\hline
\end{tabular}

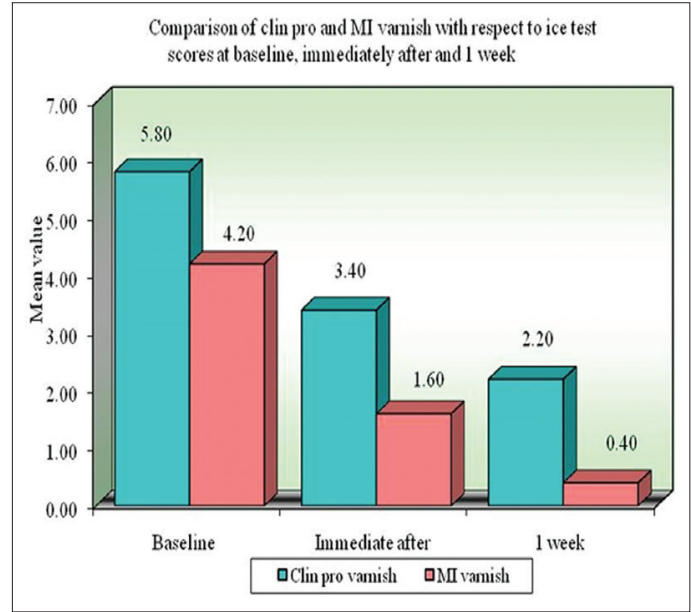

Graph 1: Comparison of Ice Test Scores

$14^{\circ} \mathrm{C}$ and $26^{\circ} \mathrm{C}$, directed at a distance of $1-3 \mathrm{~mm}$ from the exposed buccal cervical root surface. This is a method which has been used in other studies of tooth sensitivity ${ }^{[17,18]}$ It has been recommended that at least two stimuli should be used, the least severe first followed by the second and there should be little or no interaction between the two stimuli. Thus, a second stimulus has been used in this study in the form of cold water and a time gap of $5 \mathrm{~min}$ has been advised in between the two tests.

Discomfort from dentine hypersensitivity is a common finding in the adult population, with the available

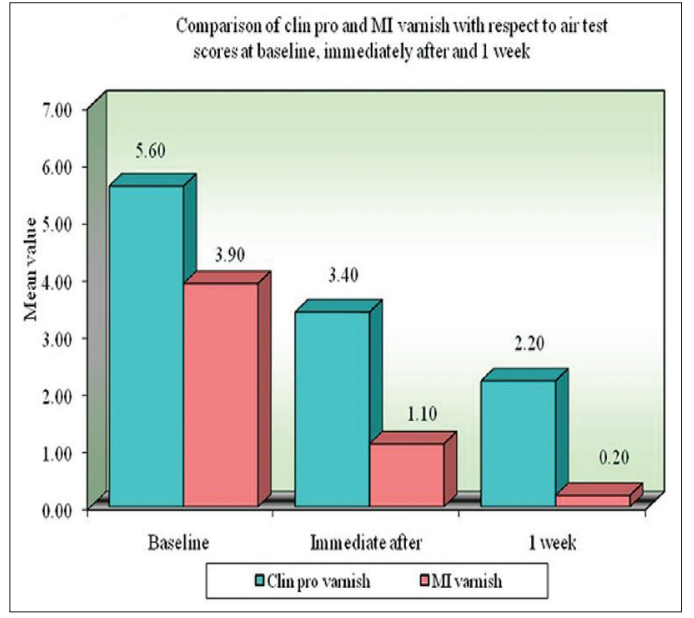

Graph 2: Comparison of Air Test Scores

prevalence data ranging from $8 \%$ to $57 \%$. The diversity of reports may be caused by different methods used to diagnose the condition, and it is generally considered that surveys which rely on patient questionnaires alone greatly exaggerate the prevalence figures, thereby yielding misleading data. ${ }^{[19-22]}$ Indeed, those studies which employed careful patient examinations produced surprisingly similar prevalence figures of around $15 \%$. In periodontal patients, cervical dentinal hypersensitivity was found to be ranging between $72.5 \%$ and $98 \%$. ${ }^{[23,24]}$

Dentinal hypersensitivity is a common although severe problem still there is limited evidence for 
the treatments used, with sensitivity returning soon after treatment. Furthermore, the amount of clinical time devoted to the management of this problem is of utmost importance. The cost-effectiveness of materials used here when compared to that of other forms of professional intervention is considerable due to the minimum clinical time required and the comparatively low cost of the material. ${ }^{[25]}$

The authors recognize that this is a 1-week follow-up study, so studies with a longer term of observation and good design are required to help to determine how often the varnish has to be reapplied. In addition, the authors also recognize that restorative materials still have a role to play in the management of dentinal hypersensitivity particularly in cases where varnishes and desensitizing agents have been ineffective or their benefits are short lived but again further research is needed.

\section{CONCLUSION}

Although, both MI and Clinpro Varnish show decrease in dentinal hypersensitivity, going by the statistics, it has to stated here that MI Varnish is a better treatment option when compared to Clinpro XT Varnish.

\section{Financial support and sponsorship}

Nil.

\section{Conflicts of interest}

There are no conflicts of interest.

\section{REFERENCES}

1. Porto IC, Andrade AK, Montes MA. Diagnosis and treatment of dentinal hypersensitivity. J Oral Sci 2009;51:323-32.

2. Brännström M. Sensitivity of dentine. Oral Surg Oral Med Oral Pathol 1966;21:517-26.

3. Madhavan S, Nayak M, Shenoy A, Shetty R, Prasad K. Dentinal hypersensitivity: A comparative clinical evaluation of CPP-ACP F, sodium fluoride, propolis, and placebo. J Conserv Dent 2012;15:315-8.

4. Clark DC, Hanley JA, Geoghegan S, Vinet D. The effectiveness of a fluoride varnish and a desensitizing toothpaste in treating dentinal hypersensitivity. J Periodontal Res 1985;20:212-9.

5. Pandit N, Gupta R, Bansal A. Comparative evaluation of two commercially available desensitizing agents for the treatment of dentinal hypersensitivity. Indian J Dent Res 2012;23:778-83.

6. Sethna GD, Prabhuji ML, Karthikeyan BV. Comparison of two different forms of varnishes in the treatment of dentine hypersensitivity: A subject-blind randomised clinical study. Oral Health Prev Dent
2011;9:143-50.

7. Olusile AO, Bamise CT, Oginni AO, Dosumu OO. Short-term clinical evaluation of four desensitizing agents. J Contemp Dent Pract 2008;9:22-9.

8. Zhou SL, Zhou J, Watanabe S, Watanabe K, Wen LY, Xuan K. In vitro study of the effects of fluoride-releasing dental materials on remineralization in an enamel erosion model. J Dent 2012;40:255-63.

9. Prabhakar AR, Manojkumar AJ, Basappa N. In vitro remineralization of enamel subsurface lesions and assessment of dentine tubule occlusion from $\mathrm{NaF}$ dentifrices with and without calcium. J Indian Soc Pedod Prev Dent 2013;31:29-35.

10. Yilmaz HG, Kurtulmus-Yilmaz S, Cengiz E, Bayindir H, Aykac Y. Clinical evaluation of Er, Cr: YSGG and GaAlAs laser therapy for treating dentine hypersensitivity: A randomized controlled clinical trial. J Dent 2011;39:249-54.

11. Allen EP. Noncarious cervical lesions: Graft or restore? J Esthet Restor Dent 2005;17:332-4.

12. Hawker GA, Mian S, Kendzerska T, French M. Measures of adult pain: Visual Analog Scale for Pain (VAS Pain), Numeric Rating Scale for Pain (NRS Pain), McGill Pain Questionnaire (MPQ), Short-Form McGill Pain Questionnaire (SF-MPQ), Chronic Pain Grade Scale (CPGS), Short Form-36 Bodily Pain Scale (SF-36 BPS), and Measure of Intermittent and Constant Osteoarthritis Pain (ICOAP). Arthritis Care Res (Hoboken) 2011;63 Suppl 11:S240-52.

13. Hoang-Dao BT, Hoang-Tu H, Tran-Thi NN, Koubi G, Camps J, About I. Clinical efficiency of a natural resin fluoride varnish (Shellac F) in reducing dentin hypersensitivity. J Oral Rehabil 2009;36:124-31.

14. Gaffar A. Treating hypersensitivity with fluoride varnish. Compend Contin Educ Dent 1999;20 1 Suppl: 27-33.

15. Johnson RH, Zulqar-Nain BJ, Koval JJ. The effectiveness of an electro-ionizing toothbrush in the control of dentinal hypersensitivity. J Periodontol 1982;53:353-9.

16. Borges AB, Barcellos DC, Torres CR. Dentin hypersensitivity-Etiology, treatment possibilities and other related factors: A literature review. World J Dent 2012;3:60-7.

17. Yates RJ, Newcombe RG, Addy M. Dentine hypersensitivity: A randomised, double-blind placebo-controlled study of the efficacy of a fluoride-sensitive teeth mouthrinse. J Clin Periodontol 2004;31:885-9.

18. Yates R, Ferro R, Newcombe RG, Addy M. A comparison of a reformulated potassium citrate desensitising toothpaste with the original proprietary product. J Dent 2005;33:19-25.

19. Flynn J, Galloway R, Orchardson R. The incidence of 'hypersensitive' teeth in the West of Scotland. J Dent 1985;13:230-6.

20. Fischer C, Fischer RG, Wennberg A. Prevalence and distribution of cervical dentine hypersensitivity in a population in Rio de Janeiro, Brazil. J Dent 1992;20:272-6.

21. Irwin CR, McCusker P. Prevalence of dentine hypersensitivity in a general dental population. J Ir Dent Assoc 1997;43:7-9.

22. Liu HC, Lan WH, Hsieh CC. Prevalence and distribution of cervical dentin hypersensitivity in a population in Taipei, Taiwan. J Endod 1998;24:45-7.

23. Chabanski MB, Gillam DG, Bulman JS, Newman HN. Clinical evaluation of cervical dentine sensitivity in a population of patients referred to a specialist periodontology department: A pilot study. J Oral Rehabil 1997;24:666-72.

24. Ozen T, Orhan K, Avsever H, Tunca YM, Ulker AE, Akyol M. Dentin hypersensitivity: A randomized clinical comparison of three different agents in a short-term treatment period. Oper Dent 2009;34:392-8.

25. Adriaens PA, De Boever JA, Loesche WJ. Bacterial invasion in root cementum and radicular dentin of periodontally diseased teeth in humans. A reservoir of periodontopathic bacteria. J Periodontol 1988;59:222-30. 